\title{
Washcoat overlayer for improved activity and stability of natural gas vehicle monolith catalysts operating in the presence of $\mathrm{H}_{2} \mathrm{O}$ and $\mathrm{SO}_{2}$.
}

Hamad Almohamadi ${ }^{a, b}$, Majed A. Alamoudi a,c and Kevin J. Smith ${ }^{a, *}$

a Department of Chemical and Biological Engineering, University of British Columbia,

2360 East Mall, Vancouver, British Columbia V6T 1Z3, Canada

${ }^{b}$ Department of Chemical Engineering, Faculty of Engineering, Islamic University of

Madinah, Madinah 42315, Saudi Arabia

${ }^{c}$ Department of Chemical and Materials Engineering, Faculty of Engineering, King

Abdulaziz University, P.O. Box 80204, Jeddah 21589, Saudi Arabia

*email:kjs@mail.ubc.ca 
Table S1: Nominal composition of monolith catalysts

\begin{tabular}{lcccccccc}
\hline Sample & Washcoat & Overlayer & $\mathrm{Pd}$ & $\mathrm{Pt}$ & $\mathrm{Ce}$ & $\gamma$-AlOOH & $\gamma-\mathrm{Al}_{2} \mathrm{O}_{3}$ & Cordierite \\
\cline { 4 - 9 } & $\mathrm{g}$ & $\mathrm{g}$ & & & & mass $\%$ & & \\
\hline Pd-WC & 0.27 & 0 & 0.35 & - & - & 5.45 & 21.2 & 73.0 \\
PdCe-WC & 0.27 & 0 & 0.35 & - & 1.5 & 5.0 & 20.15 & 73.0 \\
PdPtCe-WC & 0.27 & 0 & 0.31 & 0.04 & 1.5 & 5.0 & 20.15 & 73.0 \\
O-Pd-WC & 0.27 & 0.10 & 0.30 & - & - & 6.3 & 25.4 & 68.0 \\
O-PdCe-WC & 0.27 & 0.10 & 0.30 & - & 1.3 & 6.2 & 25.2 & 67.0 \\
O-PdPtCe-WC & 0.27 & 0.10 & 0.27 & 0.03 & 1.3 & 6.2 & 25.2 & 67.0 \\
PdCe-2WC & 0.37 & - & 0.30 & - & 1.3 & 6.2 & 25.2 & 67.0 \\
\hline
\end{tabular}


Table S2: Textural properties of the washcoat monolith catalysts before and after TPO reaction and TOS test for $24 \mathrm{~h}$ at $500{ }^{\circ} \mathrm{C}$ in the presence of $10 \mathrm{vol} \% \mathrm{H}_{2} \mathrm{O}$ and $5 \mathrm{ppm} \mathrm{SO}_{2}$.

\begin{tabular}{|c|c|c|c|c|c|c|}
\hline \multirow[t]{4}{*}{ Sample } & \multicolumn{3}{|l|}{ Fresh } & \multicolumn{3}{|c|}{ Used $^{\mathrm{a}}$} \\
\hline & BET & Pore & Average Pore & BET & Pore & Average Pore \\
\hline & area & volume & Diameter & area & volume & Diameter \\
\hline & $\mathrm{m}^{2 /} \mathrm{g}$ & $\mathrm{cm}^{3} / \mathrm{g}$ & $\mathrm{nm}$ & $\mathrm{m}^{2 / \mathrm{g}}$ & $\mathrm{cm}^{3} / \mathrm{g}$ & $\mathrm{nm}$ \\
\hline $\mathrm{Pd}-\mathrm{WC}$ & 69 & 0.17 & 10 & 35 & 0.08 & 6 \\
\hline PdCe-WC & 64 & 0.12 & 8 & 43 & 0.07 & 6 \\
\hline PdPtCe-WC & 65 & 0.16 & 10 & 48 & 0.07 & 8 \\
\hline O-Pd-WC & 84 & 0.17 & 8 & 49 & 0.12 & 10 \\
\hline O-PdCe-WC & 80 & 0.15 & 7 & 51 & 0.15 & 11 \\
\hline O-PdPtCe-WC & 82 & 0.16 & 8 & 50 & 0.14 & 11 \\
\hline PdCe-2WC & 91 & 0.17 & 7 & - & - & - \\
\hline
\end{tabular}

aUsed catalysts were recovered after the TPO test and TOS for $24 \mathrm{~h}$ in the presence of $10 \mathrm{vol} \%$ $\mathrm{H}_{2} \mathrm{O}$ and 5 ppm $\mathrm{SO}_{2}$ at $500{ }^{\circ} \mathrm{C}$ 
Table S3: EDX elemental analysis of the monolith catalysts

\begin{tabular}{|c|c|c|c|c|c|}
\hline & $\mathrm{O}, \mathrm{wt} \%$ & $\mathrm{Al}, \mathrm{wt} \%$ & $\mathrm{Ce}, \mathrm{wt} \%$ & $\mathrm{Pd}, \mathrm{wt} \%$ & $\mathrm{~S}, \mathrm{wt} \%$ \\
\hline PdPtCe-WC & $48.6 \pm 1.0$ & $45.2 \pm 1.0$ & $5.3 \pm 0.4$ & $0.9 \pm 0.2$ & 0 \\
\hline PdPtCe-WC-Used ${ }^{\mathrm{a}}$ & $46.8 \pm 0.6$ & $44.3 \pm 1.2$ & $6.4 \pm 0.7$ & $1.2 \pm 0.3$ & $1.3 \pm 0.4$ \\
\hline O-PdPtCe-WC & $51.9 \pm 1.0$ & $47.85 \pm 1.5$ & $0.18 \pm 0.05$ & $0.07 \pm 0.03$ & 0 \\
\hline O-PdPtCe-WC-Used ${ }^{\mathrm{a}}$ & $49.8 \pm 1.2$ & $47.54 \pm 1.0$ & $0.65 \pm 0.12$ & $0.13 \pm 0.07$ & $1.9 \pm 0.5$ \\
\hline
\end{tabular}


Table S4: Summary of XPS analysis of monolith catalysts

\begin{tabular}{|c|c|c|c|c|c|}
\hline \multirow{2}{*}{$\begin{array}{l}\text { Catalyst } \\
\text { Pd-WC }\end{array}$} & \multicolumn{3}{|c|}{ atom $\%$} & $\mathrm{Pd} / \mathrm{Al}$ & $\mathrm{S} / \mathrm{Al}$ \\
\hline & 0.16 & - & - & 0.41 & - \\
\hline Pd-WC - used ${ }^{a}$ & 0.16 & - & 1.6 & 0.45 & 4.6 \\
\hline O-Pd-WC & 0 & - & - & - & - \\
\hline O-Pd-WC - used & 0 & - & 2.2 & 0 & 6.5 \\
\hline PdCe-WC & 0.20 & 0.90 & - & 0.62 & - \\
\hline PdCe-WC - used & 0.68 & 0.32 & 1.7 & 2.1 & 5.2 \\
\hline O-PdCe-WC & 0 & 0 & - & - & - \\
\hline O-PdCe-WC - used & 0.10 & 0 & 1.5 & 0.30 & 4.4 \\
\hline PdPtCe-WC & 0.17 & 0.21 & - & 0.43 & - \\
\hline PdPtCe-WC - used & 0.53 & 0.27 & 1.1 & 1.53 & 3.2 \\
\hline O-PdPtCe-WC & 0 & 0 & - & - & - \\
\hline O-PdPtCe-WC - used & 0 & 0 & 1.6 & 0 & 4.3 \\
\hline PdCe-2WC & 0.13 & 0.30 & - & 0.36 & - \\
\hline
\end{tabular}




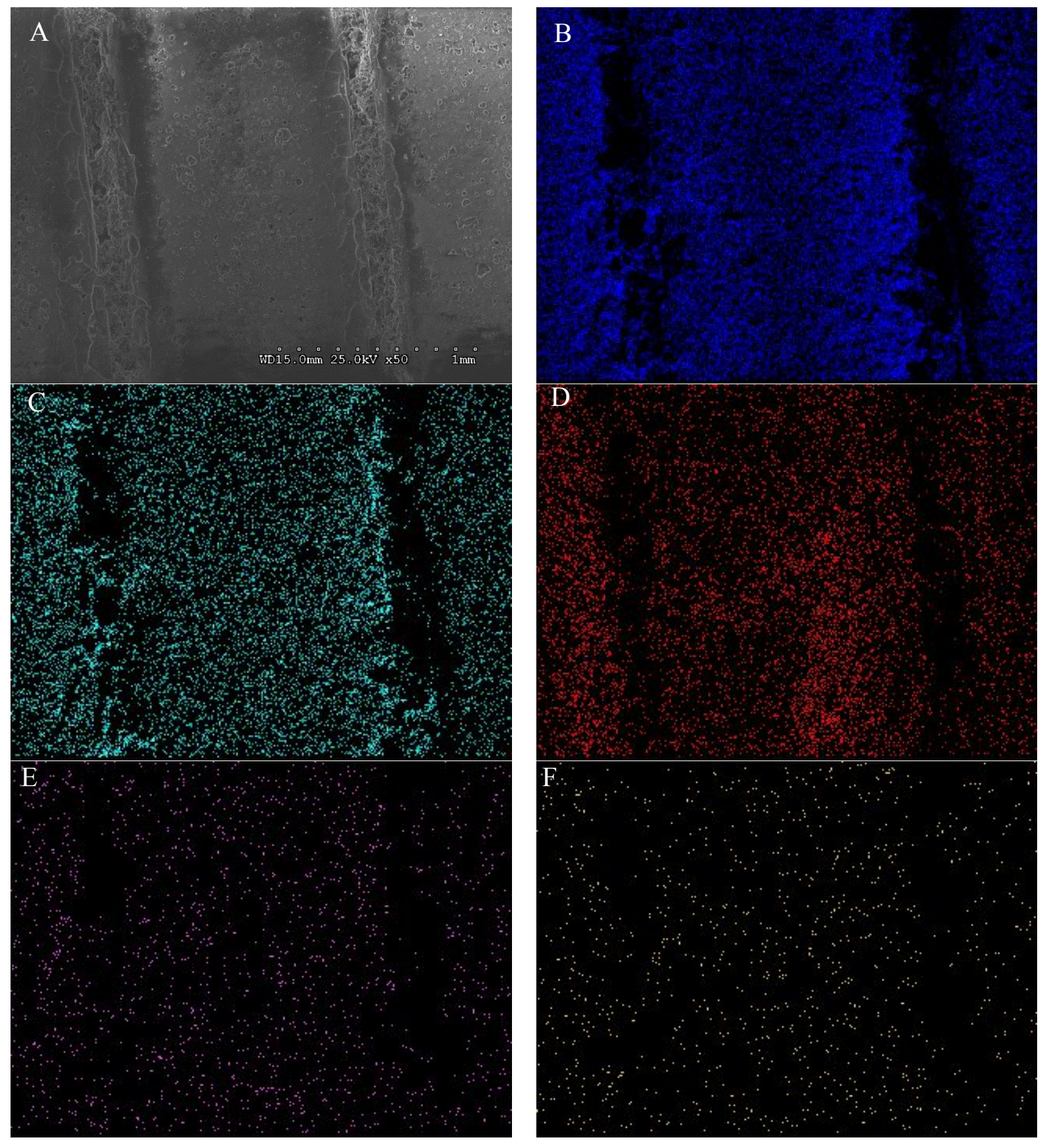

Figure S1: SEM/EDX mapping of sectioned PdPtCe-WC monolith catalyst after use: A: SEM of the washcoat; $\mathrm{B}-\mathrm{Al}$; C - O; D - Ce; E - Pd and F-S. 

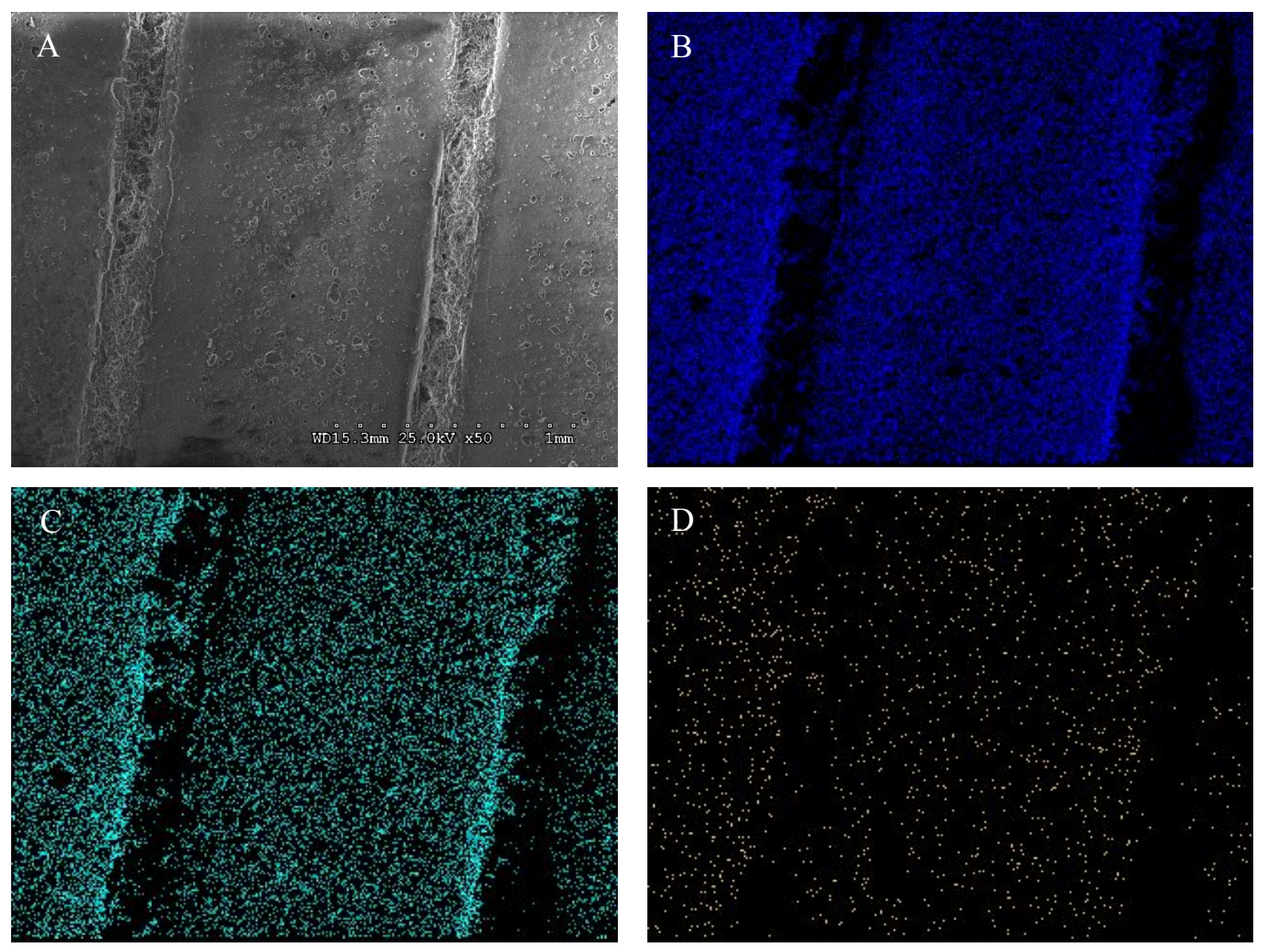

Figure S2: SEM/EDX mapping of sectioned O-PdPtCe-WC monolith catalyst after use: A -SEM of the washcoat; B - Al, C - O; and D - S. 


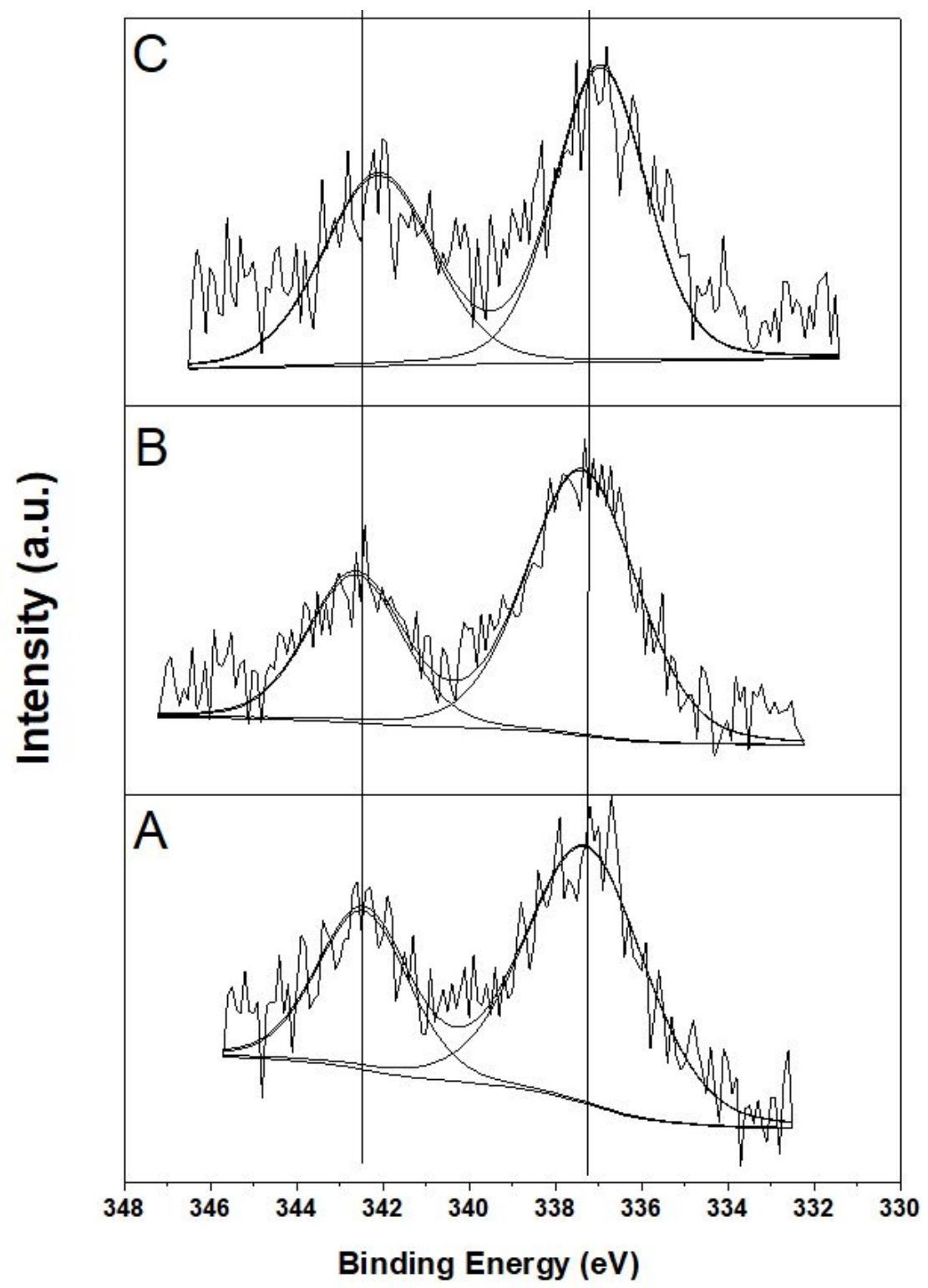

Figure S3: XPS Pd 3d spectra measured for fresh (A) Pd-WC, (B) O-Pd-WC, (C) PdPt-WC catalysts 


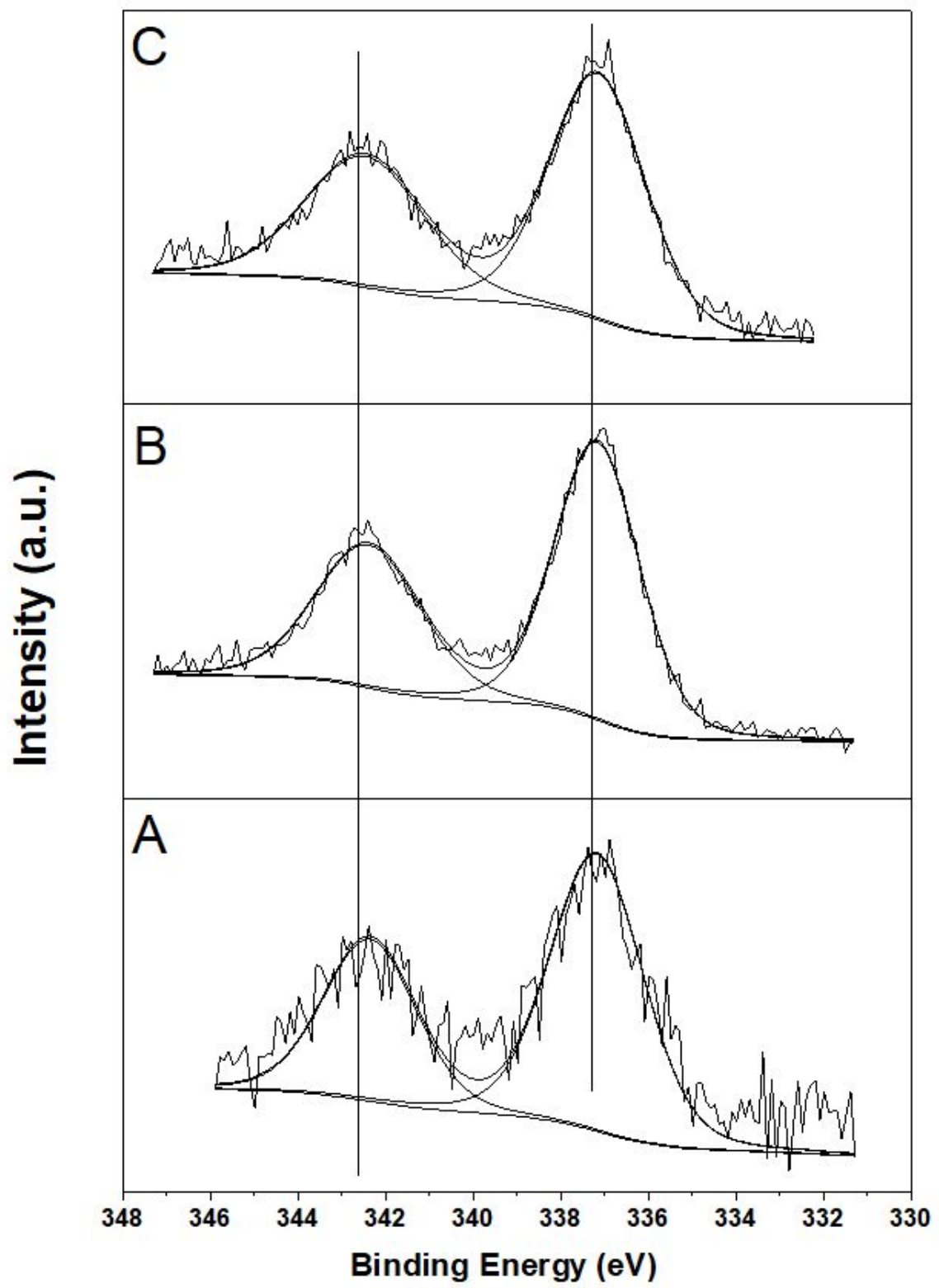

Figure S4: XPS Pd 3d spectra measured for used (A) Pd-WC, (B) O-Pd-WC, (C) PdPt-WC catalysts 


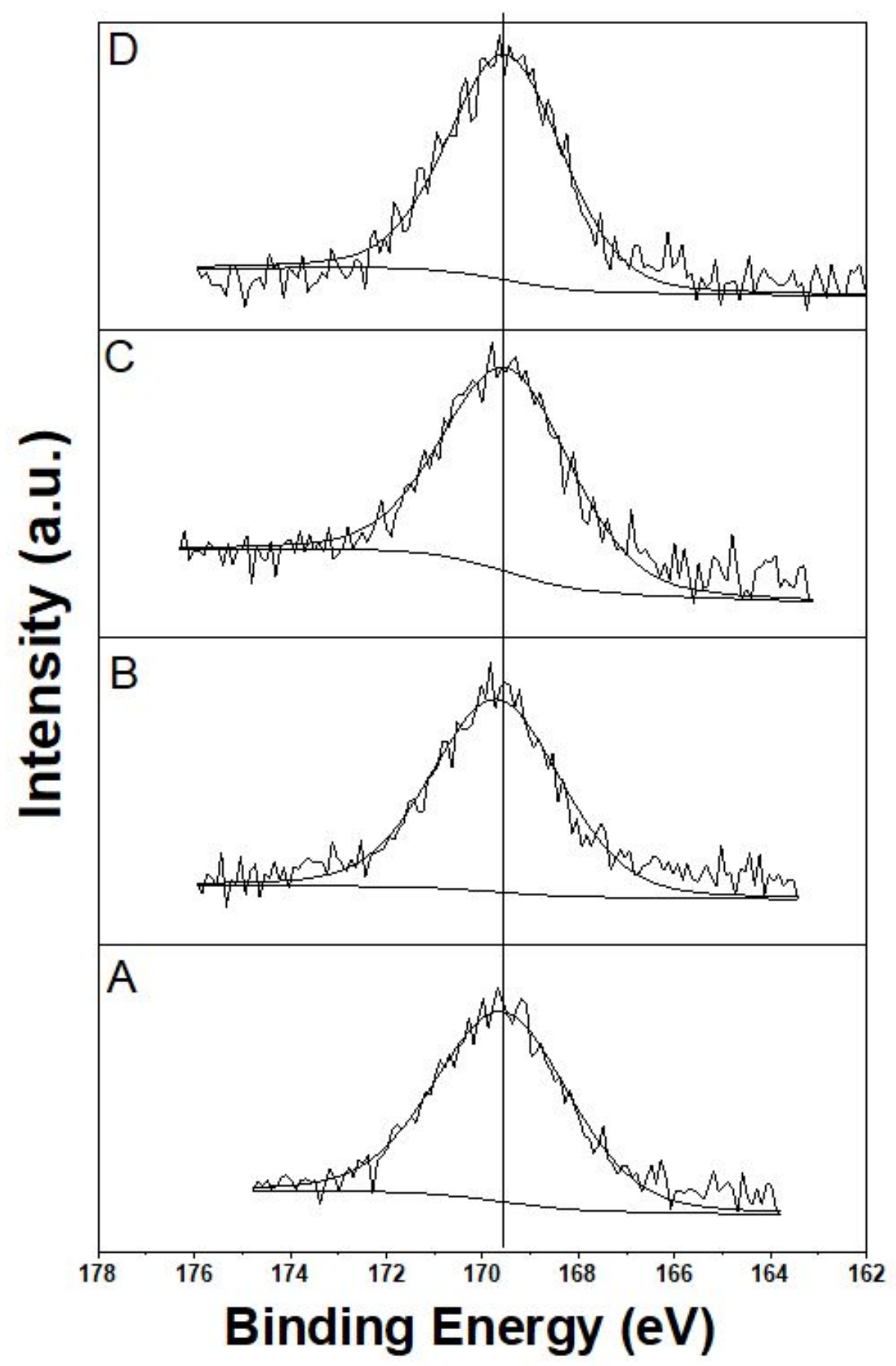

Figure S5: XPS S 2p spectra measured for used catalysts (A) PdWC, (B) O-PdWC, (C) PdCeWC and, (D) O-PdCeWC catalysts 

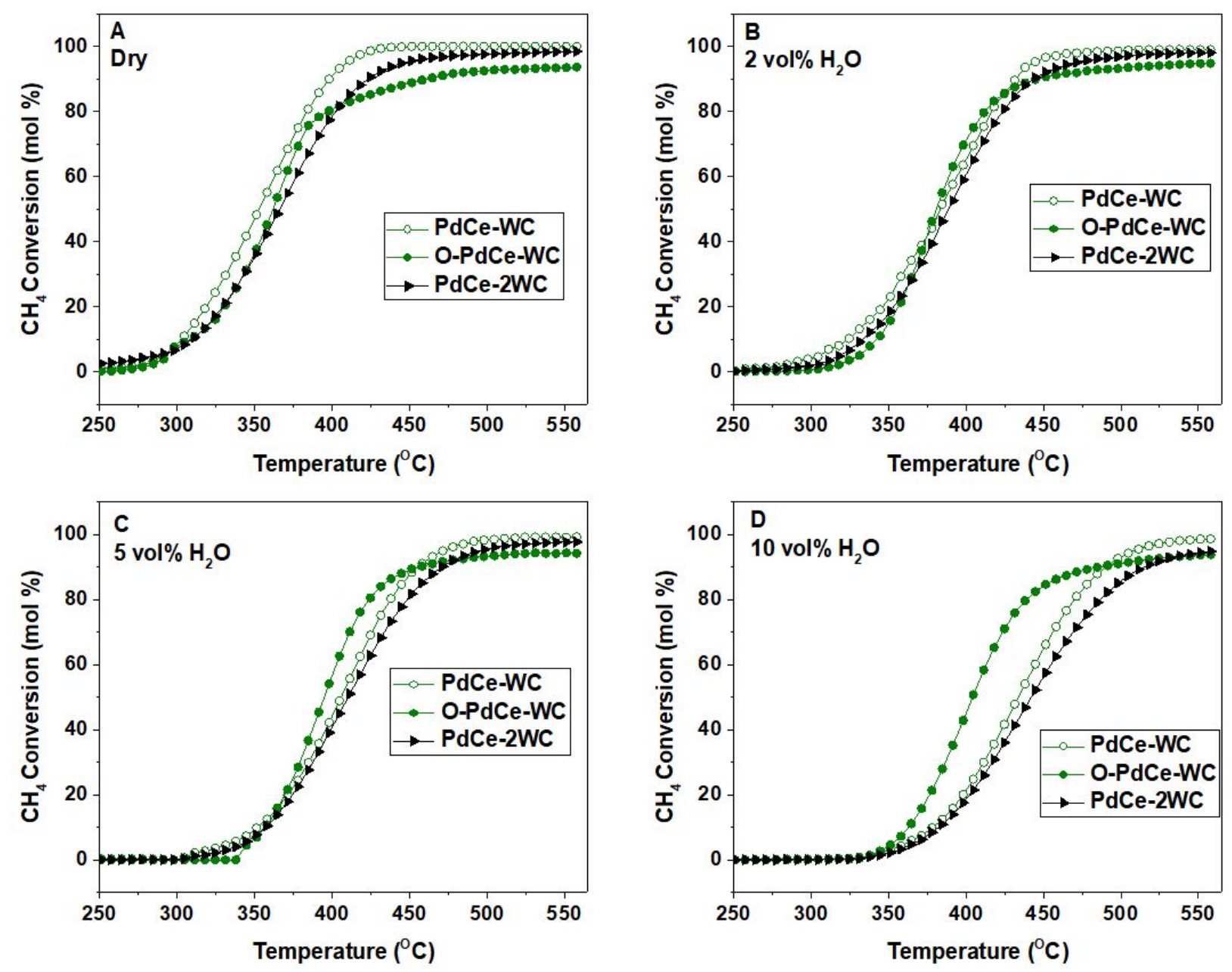

Figure S6: Temperature-programmed oxidation profile: the initial activity of the catalysts as a function of temperature. The total feed gas flow is $1025 \mathrm{~cm}^{3}$ (STP) $\cdot \mathrm{min}^{-1}$, corresponding to a GHSV of $36000 \mathrm{~h}^{-1}$ with $0.07 \mathrm{vol} \% \mathrm{CH}_{4}, 8.5 \mathrm{vol} \% \mathrm{O}_{2}, 0.06 \mathrm{vol} \% \mathrm{CO}, 8 \mathrm{vol} \% \mathrm{CO}_{2}$ and $0,2,5$ or $10 \mathrm{vol} \% \mathrm{H}_{2} \mathrm{O}$ in $\mathrm{N}_{2}$ and He. (A) Dry feed 0 vol $\% \mathrm{H}_{2} \mathrm{O}$, (B) Wet feed 2 vol $\% \mathrm{H}_{2} \mathrm{O}$, (C) Wet feed 5 vol $\% \mathrm{H}_{2} \mathrm{O}$ and (D) Wet feed 10 vol $\% \mathrm{H}_{2} \mathrm{O}$ 

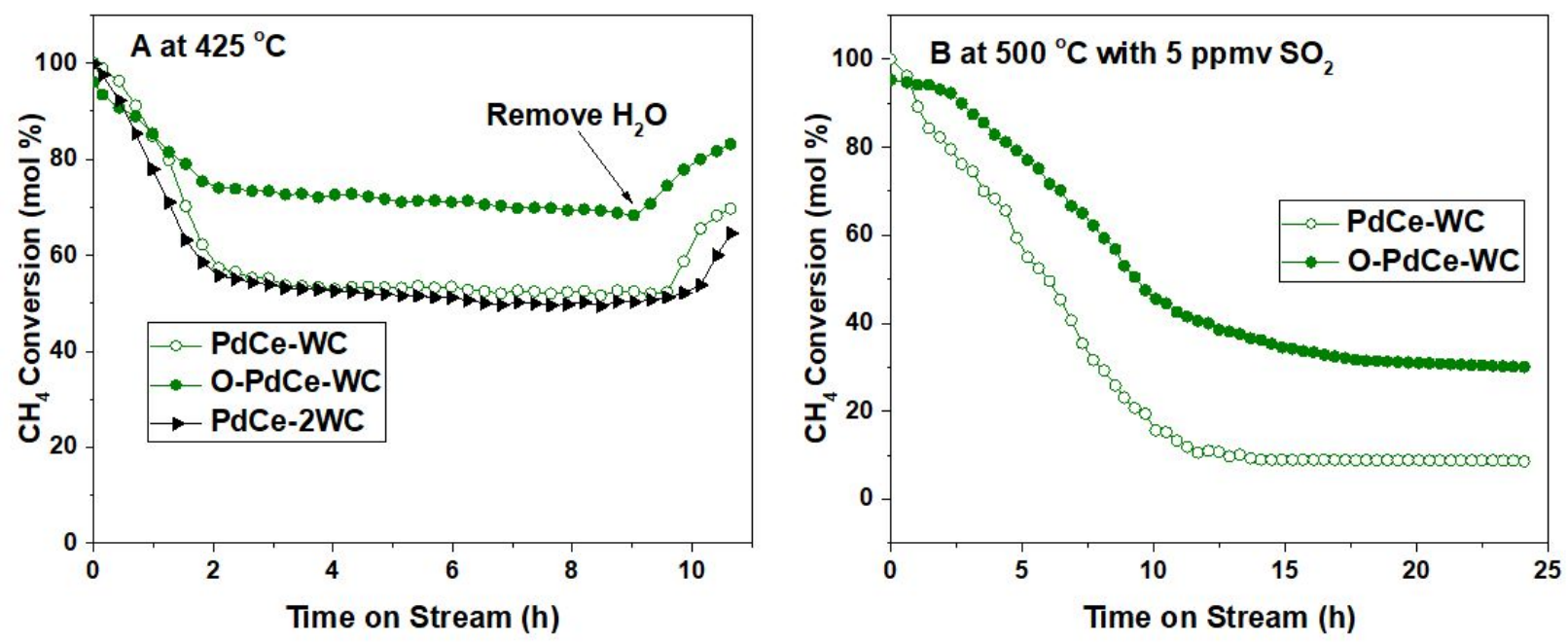

Figure S7: TOS results for adding $10 \mathrm{vol} \% \mathrm{H}_{2} \mathrm{O}$ and $5 \mathrm{ppm} \mathrm{SO}_{2}$. The total feed gas flow is 1025 $\mathrm{cm}^{3}(\mathrm{STP}) \cdot \mathrm{min}^{-1}$, corresponding to a GHSV of $36000 \mathrm{~h}^{-1}$ with $0.07 \mathrm{vol} \% \mathrm{CH}_{4}, 8.5 \mathrm{vol} \% \mathrm{O}_{2}$,

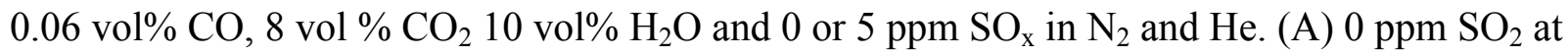
$425^{\circ} \mathrm{C}$ for $10 \mathrm{~h}$ and (B) $5 \mathrm{ppm} \mathrm{SO}_{2}$ at $500{ }^{\circ} \mathrm{C}$ for $24 \mathrm{~h}$ 


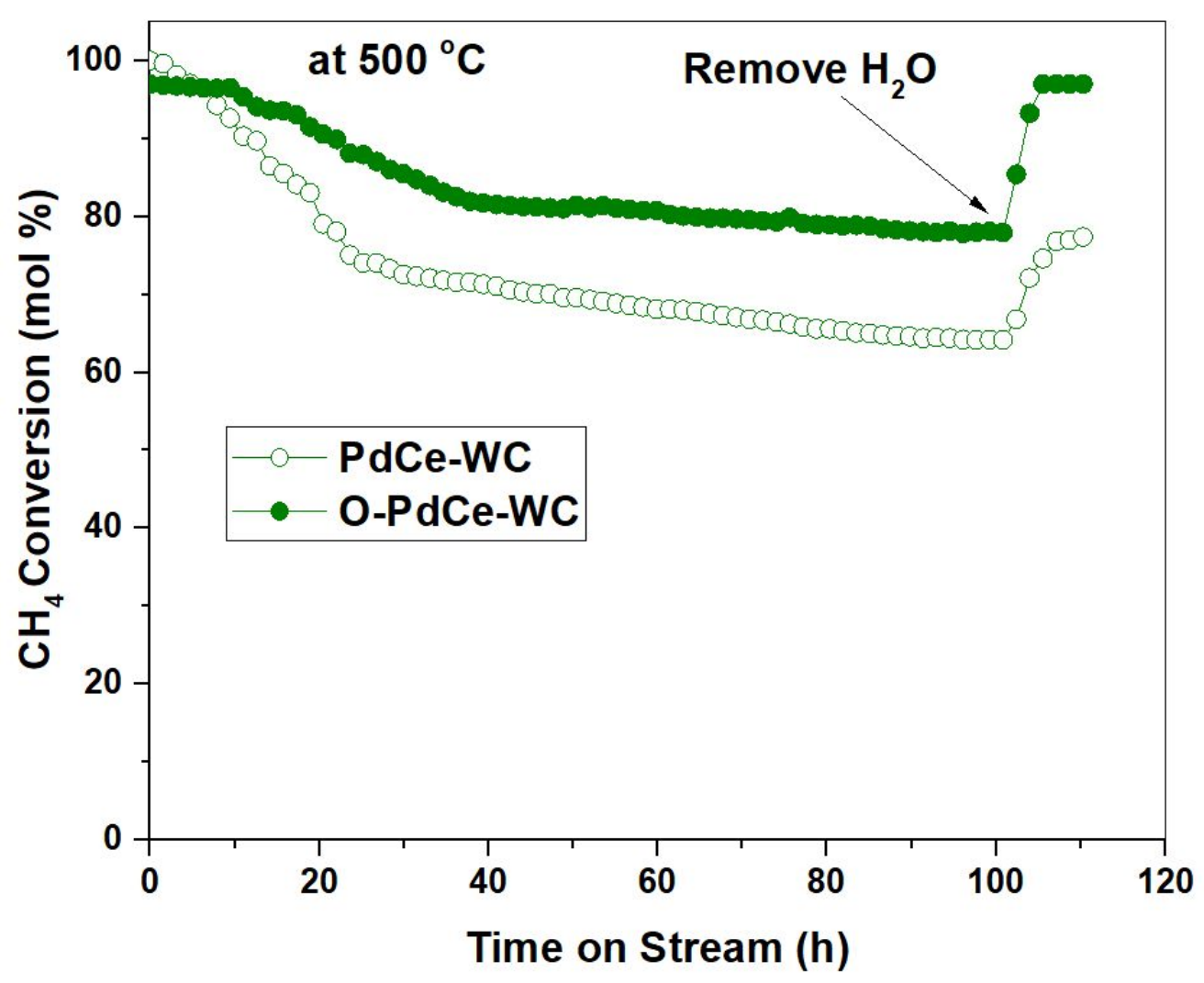

Figure S8: TOS results for adding $10 \mathrm{vol} \% \mathrm{H}_{2} \mathrm{O}$ to the feed at $500{ }^{\circ} \mathrm{C}$. The total feed gas flow is $1025 \mathrm{~cm}^{3}(\mathrm{STP}) \cdot \mathrm{min}^{-1}$, corresponding to a GHSV of $36000 \mathrm{~h}^{-1}$ with $0.07 \mathrm{vol} \% \mathrm{CH}_{4}, 8.5 \mathrm{vol} \%$ $\mathrm{O}_{2}, 0.06 \mathrm{vol} \% \mathrm{CO}, 8$ vol $\% \mathrm{CO}_{2}$ and $10 \mathrm{vol} \% \mathrm{H}_{2} \mathrm{O}$ in $\mathrm{N}_{2}$ and $\mathrm{He}$. 